\title{
Ferramentas do design de serviços para área de vendas.
}

Tools of service design for sales area.

VAZ, Franciele; Discente do Programa de Mestrado Profissional em Design; Universidade da Região de Joinville

franciele_vaz@hotmail.com

AGUIAR, Victor Rafael Laurenciano Aguiar; Doutor em Educação; Universidade da Região de Joinville

contato@ograndevendedor.com.br

\section{Resumo}

Este artigo é um recorte de relatório técnico, desenvolvido inicialmente como investigação junto ao Mestrado Profissional em Design intitulado "Diretrizes para projeto de design de serviços na área de vendas na industria de bens intermediários". Seu desenvolvimento objetiva oferecer aos gestores ferramentas do design de serviços, para possibilitar uma melhor gestão a equipe comercial por meio dos clientes. Considera-se que , este processo poderá auxiliar e talvez assegurar a sobrevivência das organizações em seus mercados.

Palavras Chave: vendedor; prestador de serviços e design de serviço.

\section{Abstract}

This article is a technical report clipping, initially developed as an investigation with the Professional Master in Design entitled "Design Guidelines for Design Services in the Sales Area in the Intermediary Industry". Its development aims to offer managers service design tools to enable better management of the sales team through clients. It is considered that this process could help and perhaps ensure the survival of organizations in their markets.

Keywords: seller; Service provider and service design. 
Análise de cenário

A necessidade do ser humano expressar-se fez com que a evolução da prestação de serviço promovesse um grande avanço na economia pois de acordo com o SEBRAE (web, 2017) o setor de serviços já corresponde a $67,4 \%$ do produto interno bruto (PIB) brasileiro seguindo uma tendência global.

Por meio do processo de vendas, criou-se um poderoso meio para divulgar informações, o que ocasionou também crescimento na economia, pois está diretamente ligado a todos os setores da indústria. Segundo Siqueira (2005) é de conhecimentos dos empresários, que a equipe de vendas constitui-se no principal instrumento de comunicação com os mercados industriais. Por intermédio da comunicação o produto se manifesta em um sistema de ideias, valores e normas, onde o vendedor tem o papel fundamental de comunicar, informar e simbolizar.

Nos primórdio históricos a venda industrial baseava-se no produto visando unicamente o lucro. Na contemporaneidade percebe-se a mudança, de cultura e valores dentro das organizações, principalmente na evolução do vendedor para prestador de serviços, o vendedor industrial não oferece somente um produto ou serviço, mas um conjunto de fatores que resolvem um problema ou atendem a uma necessidade do cliente. A partir do momento em que o profissional de vendas representa uma empresa, entende e responde às demandas do cliente, orienta-os e os apoia no entendimento das suas ofertas de acordo com Ênio Klein (web, 2015) gerente geral nas operações de vendas da Sales Way no Brasil "o vendedor se torna um prestador de serviço".

A partir dessa mudança de cultura, o vendedor tornou-se um profissional mais capacitado, desvinculando-se da figura de marginal e valorizando sua imagem perante a sociedade. Isso ocorreu por anseio dos clientes mas, especialmente pela influência das industrias se reestruturando após a segunda guerra mundial. Somado a isso, a influência de fatores econômicos, sociais, culturais, políticos e tecnológicos, o vendedor remodelou-se para corresponder um vasto conjunto de deficiências de seus clientes antes, durante e após as vendas.

Diante desse cenário, uma grande dificuldade para as empresas é sobreviver no mercado industrial, pois é preciso atender diariamente essas novas demandas. Sendo assim, este artigo tem a finalidade de apresentar ferramentas do design de serviços uteis para gestão do vendas, pois por meio do design de serviço, as organizações podem criar vantagens competitivas, clientes fiéis, satisfeitos e maiores margens de lucro alem de fornecer ferramentas para criar uma visão geral da situação, gerando entendimento mútuo, aprimorando operações e direcionando recursos.

\section{A origem do vendedor}

Embora existam vestígios arqueológicos que permitam suposições da origem da venda mesmo antes da escrita, foi a partir da revolução industrial que o profissional de vendas passou a ter maior representatividade. Para Pestana (web, 2017) a sedentarização trouxe transformações perceptíveis na organização social, cultura e religião; os agrupamentos humanos se tornaram mais numerosos, comportando uma explosão demográfica que originou as primeiras cidades e, posteriormente, as primeiras civilizações. 


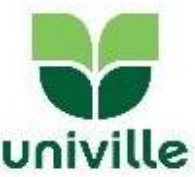

Nos primeiros grupos, subdividia-se as tarefas por idade e sexo; às mulheres designavase a tarefa de coletar frutas e raízes, cuidar das crianças e o preparo dos alimentos; aos homens a caça e a pesca, a preparação de artefatos para facilitar a caça, como lanças e machados de pedra, aos caçadores designava-se a função de distribuição da carne, até certa época influenciada pelo grau de parentesco, aliança e devolução de favores. Nessa fase os homens eram nômades, migrando atrás de caça e pesca.

Da pré-história até a revolução neolítica, fixando-se em aldeias próximas a fontes de água e terras férteis, iniciou-se então a domesticação de plantas e animais, com a agricultura e o pastoreio, em pouco tempo, aprimorou-se técnicas de construção de moradias, criando peças de cerâmicas para armazenar alimentos e servir como decoração, simultaneamente, começouse a aperfeiçoar instrumentos agrícolas, o que gerou excedente e possibilitou o início do comércio, forçando o aparecimento de novas tecnologias para o transporte das mercadorias.

A história confirma que, na época primitiva, era normal a partilha e a troca de produtos abundantes; com a prosperidade nas trocas, houve também uma evolução no próprio conceito de trocas. De acordo Cobra (1984, p. 197) "a troca foi, sem dúvida, o primeiro ato do comercio. Ela se confunde com a própria história do mundo, sendo o comercio uma das mais antigas atividades humanas".

O comércio nos primórdios históricos, chegou no Brasil, junto com seu descobrimento, quando a troca era utilizada para aproximação com os índios, a partir de 1500 até 1822, o país foi colônia de Portugal, começando a dependência histórica do mercado exterior, pois a metrópole proibia o estabelecimento de fabricas no território, para que os brasileiros consumissem exclusivamente produtos manufaturados portugueses, "mesmo com a chegada da família real em 1808 e a abertura dos portos às nações amigas, o Brasil continuou dependendo do exterior a começar pelos ingleses" (Loureiro, 2008, p. 67)

A venda na região era responsabilidade dos mercantes, artesãos e outras pessoas que já exerciam a atividade de vendas, eles percorriam as estradas coletando os produtos do campo para vender nas cidades e em contrapartida os produtos manufaturados nas cidades eram comercializados no campo. O mercante praticamente sustentou a vida comercial porem sempre foi visto como marginal, como a própria palavra traduz.

Sob o impacto da $2^{\mathrm{a}}$ Guerra Mundial, a prestação de serviço surgiu nos Estados Unidos, nos anos 40, iniciou-se com as parcerias industriais estabelecidas entre os países europeus e o americano para a produção de armamentos em consonância com uma nova sociedade que emergia sobre os escombros ou os reflexos da grande guerra mundial. Forty (2007) destaca que principalmente após 1850, com a influência da industrialização é que a sociedade capitalista colocou como o objetivo principal da produção de artefatos gerar lucro ao fabricante.

Segundo Hardman e Leonardi (1991, p. 33) "a indústria nacional cresceu significativamente nas décadas de 1930-40”, pois os países europeus passaram a importar produtos industrializados de outros países, entre eles o Brasil e foi durante o primeiro governo de Getúlio Vargas (1930-1945) o presidente teve como meta efetivar a industrialização do país, beneficiando as indústrias nacionais, com leis voltadas para a regulamentação do mercado de trabalho, medidas protecionistas e investimentos em infraestrutura.

Com a implantação das estradas de ferro no país, o vendedor caixeiro viajante recebe destaque e ares de personalidade, com a comunicação instável ele era o irradiador de informações. Cobra (1984) relata que esse homem era o agente de distribuição de mercadorias e de notícias da moda e de outros eventos de cunho social e político das cidades do Rio de 
Janeiro e de São Paulo.

A revolução industrial firmou-se em uma mudança completa nos paradigmas de produção: o trabalho humano substituiu-se por máquinas e grandes indústrias surgiram, produção em massa em detrimento da produção manual e artesanal percebida até então; devido a essas alterações houve um aumento de volume de produção e a vinda de concorrentes, no âmbito intermunicipal e internacional. A necessidade de escoar esses produtos e abrir novos clientes exigiu uma maior quantidade de vendedores, tornando a venda pessoal determinante para que a venda na indústria saísse de uma produção baseada na agricultura para uma economia de produção em massa. (Ingram et al, 2008)

Nesse período, segundo Spiro (2009) o vendedor ambulante era maioria na profissão, eles compravam produtos de diversos fornecedores e viajavam o país todo revendendo à pronta entrega. Porém, as novas empresas, optaram em ter uma equipe de vendas exclusiva, onde como eram conhecidos os "tiradores de pedidos" eram remunerados por comissão sobre os volumes vendidos. Diferentemente do vendedor ambulante, o tirador de pedido não venda a pronta entrega, ele fazia o papel da "pré venda", porque se anotava o pedido, recebia um pagamento de entrada e posteriormente o pedido seria entregue onde finalizava-se a compra

Até meados de 1945 não desenvolveu-se novos métodos de venda, pois foi um período marcado por duas guerras mundiais e a depressão de 1929. Com a redução da vendas devido a esses acontecimentos, os vendedores tiveram um papel muito importante: gerar receita para as empresas em um momento de crise, evitando a falência de centena de organizações.

A crise econômica, contudo, passou a impor o refinamento dos negócios e apenas empresas com vendedores agressivos resistiram ao declínio econômico. Apenas com a melhoria do pós guerra em 1945, é que as empresas investiram no aperfeiçoamento de vendas, assim considerou-se necessidade a profissionalização dos vendedores até então amadores.

$\mathrm{Na}$ contemporaneidade os profissionais de vendas deixaram de ser adversários que manipulam pessoas em proveito próprio. Eles precisam ser consultores, parceiros e agentes de solução de problemas para seus clientes. Sua meta é construir relacionamentos de longo prazo com os clientes. Os profissionais de vendas procuram beneficiar seu empregado, seus clientes e si próprio." (Futrell,2003, p. 20).

Segundo Ingram et al (2008), após esses acontecimentos as empresas passaram a ver os vendedores como colaboradores fundamentais na geração de receita e na propagação de sua imagem perante os consumidores. A função de vendas pessoal passou a ser respeitada e vista com mais profissionalismo e o vendedor passou a ser exigido em ter uma postura e conduta igualmente profissional.

\section{Vendas}

Transmitir ideias de maneira eficaz é uma característica importante para relações interpessoais e, por resultado, uma condição para a convivência de forma geral. Por meio das várias formas de comunicação a ocupação de vender se fez uma das mais antigas do mundo, no entanto, é uma das áreas que mais desenvolveu-se enquadra-se na realidade do mundo contemporâneo.

"Vender, em um sentido amplo, pode ser definido como o trabalho de transmitir um 
conceito, uma ideia ou uma proposta. Assim, todo mundo vende algo quando comunica ideias e interesses." (Ratto, 2007, p. 17). Por exemplo, no cotidiano a criança desde o nascimento potencializa métodos de comunicação para faze-la entender, entender os outros e conquistar os objetivos traçados. Esses métodos são aplicados no início inconscientemente no ambiente familiar, aperfeiçoando-se, depois na escola e mais tarde na vida profissional.

No mundo dos negócios, venda pessoal refere-se à comunicação pessoal de informações para persuadir um prospect (cliente potencial) a comprar algo, um bem, um serviço, uma ideia ou outra coisa que atenda suas necessidades individuais. Essa definição de vendas implica uma pessoa ajudando outra pessoa. (Futrell et al. 2003, p. 04)

Com essas definições mostra-se a importância da comunicação no processo de vendas. A venda é definida por Castro (2011) como "um processo de comunicação pessoal em que o vendedor identifica e satisfaz às necessidade de um comprador para o benefício de longo prazo de ambas as partes”. Segundo Czinkota (2011), venda pessoal é a comunição verbal direta concebida para explicar bens, serviços ou ideias de um pessoa ou empresa que servem às necessidades de um ou mais clientes potenciais, Czinkota (2011) ainda afirma que o processo de comunicação está na essência de uma venda, no entanto o seu papel como "distribuidor" de produtos de diversos momentos não pode ser ignorado.

\section{Design de serviços:}

O design de serviço existe desde que os serviços existem, a partir do momento em que o vendedor deixa de ser um agente distribuidor de produtos, com a habilidade de convencer alguem a comprar algo, para ter a preocupação em atender as necessidades e expectativas dos clientes. Nesse sentido o vendedor torna-se um prestador de serviços. Transformando o design de serviço essencial para o planejamento de suas atividades e dos processos organizacionais.

O design de serviço foi inserido inicialmente como uma disciplina de projeto na Escola Internacional de Kohn em 1991. Como um campo novo, a definição de design de serviço é muito ampla, De acordo com Stickdorn (2010) "se você perguntar a dez pessoas o que design serviço é, você iria acabar com onze respostas diferentes, pelo menos ".

Stickdorn (2010) apresenta o design de serviços como uma nova maneira de pensar, de forma multidisciplinar, ou seja, ele integra e vincula vários campos de estudo e compreender isso é importante por duas razões: em primeiro lugar, para apreciar o portfólio de conhecimentos que o design de serviço reúne; em segundo lugar, para compreender que essas áreas com conhecimentos relacionados fornecem ferramentas, conhecimentos, recursos e experiência existentes.

Já Mager (2009) apresenta o design de serviços como uma abordagem que compreende as atividades humanas, sentimentos, necessidades e motivações e vê que é sobre a criação de serviços na perspectiva dos utilizadores. Tecnicamente, o autor vê o design de serviços como uma abordagem empática para descobrir necessidades não satisfeitas explícitas e ocultas dos clientes e desejos que sejam utilizáveis, úteis, eficientes, eficazes e desejáveis do ponto de vista do produtor. 
Moritz (2005), por sua vez, escreve que o design de serviço pode ser entendido como uma maneira muito diferente de abordar como é pensada a relação entre organizações e clientes; por meio do design de serviço, as organizações podem criar vantagens competitivas, clientes fiéis e satisfeitos com maiores margens de lucro. Afinal, "o capital humano, e não financeiro, é o ponto de partida para qualquer estratégia de sucesso". (Di Serio e Vasconcellos, 2009, p.24)

O design de serviços está planejando e moldando experiências de serviço úteis, desejáveis e eficientes; ajuda a entender os consumidores, o mercado, os recursos disponíveis e insights sobre as expectativas dos clientes, necessidades e experiências em todos os touchpoints e ao longo do tempo; ajuda a desvendar oportunidades, produzir idéias, resolver problemas e criar soluções implementáveis.

"O design de serviço fornece especificações, diretrizes e estratégias significativas. Gera idéias, desenvolve soluções e cria conceitos. Utiliza critérios para identificar as melhores ideias e soluções. Encontra maneiras de explicar e compartilhar insights, estruturas e processos complexos. Usa a prototipagem para testar resultados, planos e mapas de processos para implementar as soluções.” (Moritz, 2005, pg 40)

Na prática, o design de serviço desempenha um papel no planejamento e organização de pessoas, da infraestrutura, na comunicação de um serviço, a fim de melhorar sua qualidade e a interação entre o vendedor, atuando como prestador de serviços nos clientes.

De acordo com Moritz (2005) o objetivo das metodologias de design de serviços é projetar de acordo com as necessidades dos clientes ou participantes, de modo que o serviço seja amigável, competitivo e relevante para os clientes.

O design de serviço fornece ferramentas para criar uma visão geral da situação, gerar entendimento mútuo, aprimorar operações e direcionar recursos. É um processo contínuo, que trabalha com componentes, oficinas e projetos para integrar novas práticas de serviço nas organizações. Efetivamente, o design de serviço se adapta às organizações e necessidades e é traduzido em estruturas e processos de negócios.

O design de serviço oferece sem distinção, a possibilidade de planejar e organizar pessoas, infraestrutura, comunicação de um serviço a fim de melhorar sua qualidade e a interação entre vendedor norteado como prestador de serviços e seus clientes.

\section{Ferramentas do design de serviço}

No que se refere à fabricação de um produto, talvez seja relativamente simples relatar o processo; pode-se iniciar com um conceito, com as funções básicas, estruturas ou mensagens associadas que irão atrair e satisfazer os consumidores. Com base nas análises do conceito o produto já se tem premissas definidas: estilo, componentes que devem ser planejados e concebidos, já tem-se modelos físicos como "mockup" para a avaliação de estilo e layout. Os protótipos são construídos e testados em termos de funcionalidade, usabilidade, viabilidade de produção, custo e preço, resposta de mercado.

O design de serviço também oferece processos. Podem iniciar-se com a exploração, que envolve entender a empresa, seus processos e problemas sob a perspectiva do cliente; a criação, depois de definido o problema, envolve os conhecedores da prestação de prestação de 
serviço, como clientes, funcionários, stakeholders gerando o maior número de ideias; a partir disso a reflexão e análise dos dados coletados, por fim, a proposta final possível de aplicação.

De acordo com Stickdorn e Schneider (2013, p.126) "embora os processos de design, sejam, na realidade não lineares, é possível articular uma estrutura geral entre eles", considerando que os processos de design para produtos físicos já estão estabelecidos, o design de serviços oferece ferramentas de diversas áreas tornando-se possível implementar projetos com uma abordagem estruturada.

Para melhor gestão do setor de vendas, o design de serviços apresenta ferramentas a partir de Moritz (2005) e Stickdorn e Schneider (2013) podendo ser utilizadas por todos os envolvidos no processo cada qual com suas especificidades:

$>$ Um dia na vida, safari de serviços, shadowing e o mapa de jornada do usuário as pessoas são convidadas a uma imersão no dia a dia da vida dos usuários, para observar o comportamento e experiências nos diversos pontos de contato por meio dos quais o comprador interage com o serviço, a diferença entre o shadowing para os demais é que ele mais observa.

$>$ Entrevistas contextuais, os 5 porquês, sondagem cultural e a etnografia móvel são conduzidas no ambiente, ou contexto, em que ocorre o processo do serviço em questão. Essas técnicas permitem que os entrevistadores observem, investiguem e registrem o comportamento no qual estão interessados.

$>$ Brainstorming em grupo, cocriação e o mapa de expectativas geralmente envolvem exercícios para estimular a participação do grupo, momento em que há abertura para investigar e mapear quando eles estão interagindo com um serviço para que haja melhoria.

$>$ Storytelling, storyboard, criação de cenários e o "E se ...?" são ferramentas que exploram a criação de cenários por meio de narrativas ou desenhos, criadas com um nível de detalhamento suficiente para explorar de maneira relevante um aspecto especifico da oferta de um serviço.

$>$ Maquete de mesa é uma réplica miniaturizada em 3D, os designers podem dar vida a uma situação, encenando situações em cenários comuns e auxiliando no desenvolvimento de protótipos.

> Protótipo de serviço e a encenação do serviço: é a simulação de uma experiência do serviço. Essas simulações podem variar, desde conversas informais no estilo "dramatização" até recriações mais detalhadas, em escala natural, envolvendo a participação ativa de usuários, acessórios de cena e pontos de contato físicos.

$>$ Mapa de ciclo de vida do usuário e blueprints de serviços são uma visualização do relacionamento entre usuário e prestador do serviço, ele pode especificar aspectos do relacionamento e detalhar aspectos do serviços, detalhando tudo, desde os pontos de contato com o usuário até os processos de retaguarda.

> Mapa de stakeholders: é uma representação visual ou física dos diversos grupos/ públicos envolvidos em determinado serviço. Ao representar dessa maneira funcionários, clientes, organizações parceiras e outros stakeholders, pode-se analisar e mapear as atividades entre esses grupos.

$>$ Personas: são perfis fictícios, muitas vezes desenvolvidos como uma maneira de representar um grupo especifico de pessoas com base em seus interesses comuns.

$>\mathrm{O}$ desenvolvimento ágil e o business model canvas são ferramentas que auxiliam na descrição, análise e design de modelos de negócios, permitem que os projetos cresçam 
e se desenvolvam ao longo do tempo, adaptando-se em torno da evolução das necessidades do cliente e dos materiais de pesquisa que o projeto pode gerar.

Cada ferramenta possui suas particularidades, abertura e necessidade do envolvimento de todos os stakeholders do processo, porem para o seu desenvolvimento deve-se lembrar que o foco é o usuário, pois é imprescindível que haja a profunda compreensão do que é essencial para transformar uma negociação numa experiência para o comprador aonde a prestação do serviço e do produto supram suas expectativas e necessidades.

A partir do uso de ferramentas como as anteriormente descritas, o design de serviço oferece uma possibilidade de inovar numa perspectiva diferente: a do usuário, com a possibilidade de visualizar e acompanhar os diversos touchpoints, medir o desempenho, melhora-lo, prototipar novos produtos, saber seu público alvo e otimizar os processos, tornando-se mais competitivo caracterizando diferenciais em relação aos concorrentes, e isto é fundamental para a área de vendas.

\section{Considerações finais:}

A falta de suporte seja material ou de conhecimento que muitos gestores não possuem no momento de implantar projetos no setor de vendas, que tragam a realidade do dia-a-dia na área de vendas, considerando todos os stakeholders dificulta a elaboração, implementação de projetos e gestão na área de vendas.

Sabe-se que a área de vendas é fundamental, não só para as organizações, mas também para a economia.

Considerando que o vendedor exerce atividades que vão além do ato de vender; ele deve constantemente estar acompanhando os clientes da base e prospectando novos clientes; deve-se envolver nas etapas do pós venda, para garantir que o comprador receba o produto certo, na data certa, no local certo dentro do horário combinado; tudo isso em contato com o mercado, para estar atualizado de todas as informações relevantes para o bom desempenho de sua função, para agregar ao comprador e manter a empresa atualizada.

O design de serviços por ser multidisciplinar viabiliza todas as ferramentas necessárias para estruturar processos, acompanhar e analisar a equipe de vendas, as ferramentas do design de serviços podem ser utilizadas para facilitar e ter controle das atividades exercidas pelo profissional de vendas, auxiliando na condução e desempenho do setor para que este seja otimizado o tempo.

Por exemplo: O vendedor ao iniciar em uma organização, por mais experiência e conhecimento do segmento que ele possua, é essencial fazer um levantamento dentro e fora de sua carteira potenciais clientes, para isso a etnografia móvel e a sondagem cultural são ferramentas que oferecem ao vendedor a possibilidade de investigar e registrar o comportamento no qual estão interessados. Posteriormente, o mapa dos stakeholders auxilia a identificar as principais pessoas que influenciam no processo de compra.

A partir dessas ferramentas apresentadas, pode-se acompanhar os clientes da base com o mapa de ciclo de vida do usuário e blueprints de serviços, por meio da visualização do relacionamento entre usuário e prestador do serviço ou até o mapa de expectativas.

Aos gestores tem-se a necessidade de ampliar os horizontes, longe da zona de conforto, e redescobrir ferramentas para a melhor condução da equipe de vendas, as aqui apresentadas 


\section{GAMPI}

para utilização pelos vendedores, do mesmo modo serve aos gestores, além de ferramentas como o protótipo de serviço, a encenação do serviço, storytelling, storyboard, criação de cenários e a maquete que podem ser apresentadas e dramatizadas em treinamentos; e o desenvolvimento ágil e o business model canvas que auxiliam na descrição, análise e design de modelos de negócios.

Em toda a história de vendas, a mola propulsora para seu desenvolvimento foi a pressão de grandes acontecimentos históricos, mesmo porque seu surgimento foi inicializado em um determinado período em que a necessidade de se comunicar e transmitir ideias estava em conflito com o entendimento de troca e lucro.

Nota-se que as características sociais, culturais e econômicas influenciaram o desenvolvimento do vendedor, tornando-o profissional. Porém, considera-se fundamental oferecer aos gestores ferramentas do design de serviços, para possibilitar um aprimoramento da gestão comercial.

Pode-se concluir que, estas ferramentas poderão auxiliar e talvez assegurar a sobrevivência das organizações em seus mercados, e que o design de serviço vem-se construindo e fortalecendo através das experiências em conjunto com o cliente, criando uma ponte estruturada de confiança e comunicação entre os envolvidos; tornando-se essencial para os processos de vendas.

\section{Referências Bibliográficas:}

CASTRO, Luciano Thomé e; NEVES, Marcos Fava. - Administração de vendas: planejamento, estratégia e gestão / Luciano Thomé e Castro, Marcos Fava Tavares. - 1.ed. - 5.reimpr. - São Paulo: Atlas, 2011.

FIELL, CHARLOTTE E PETER - Design do século XX: Tashenn Koln London Madrid New York Paris Tokio 2001

COBRA, Marcos Henrique Nogueira, 1940 - Administração de vendas/ Marcos Cobra. 2. Ed. - São Paulo: Atlas, 1984.

DI SERIO; Luiz Carlos, VASCONCELlOS; Marcos Augusto. - Estratégia e competitividade empresarial: inovação e criação de valor / Luiz Carlos di Serio, Marcos Augusto de Vasconcellos. - São Paulo: Saraiva, 2009.

FORTY, A. - Objeto de desejo - design e sociedade desde 1750: Adrian Forty; tradução Pedro Maia Soares, São Paulo: Cosac Naif,2007

FUTRELL, Charles M. - Vendas: fundamentos e novas práticas de gestão/ Charles M. Futrell; revisor técnico Marcello Chiavone Pontes. - São Paulo: Saraiva, 2003.

HARDMAN, Foot; LEONARDI, Victor. História da indústria e do trabalho no Brasil: das origens aos anos 20. 2. ed. São Paulo: Ática, 1991.

Instituto Brasileiro de Geografia e Estatísticas. Disponível em http://www.ibge.gov.br/home/>. Acessado em 28/05/2017 
INGRAM, T.N.; LA FORGE, R.W.; AVILA, R.A.; SCHWEPKER JR, C.H.; WILLIAMS, M.R. Gerenciamento de vendas: análise e tomada de decisão. São Paulo: Cengage Learning, 2008.

LOUREIRO, Felipe Pereira - As origens da indústria no Brasil / Felipe Pereira Loureiro; Editora LCTE; 2008.

LOVELOCK, Christopher; WRIGHT, Lauren - Serviços: Marketing e Gestão / Christopher Lovelock, Lauren Wright; tradução Cid Knipel Moreira; revisão técnica Mauro Neves Garcia. - São Paulo: Saraiva, 2006.

MAGER, B. - Service Design as an Emerging Field. In Miettinen, S. and Koivisto, M. Eds. (2009), Designing Services with Innovative Methods. Publication series. University of Art and Design Helsinki B 93. Kuopio Academy of Design. Taitemia Publication Series 33. Otava.

MELO, Lício de. - A Bíblia de vendas industriais / Lício de Melo. - 1. Ed. - Salto, SP: Schoba, 2013.

MORITZ, Stefan. - Service Design Practical access to an evolving field / Stefan. Moritz, London 2005.

RAMOS, Fabio Pestana. - O surgimento do homem, os primeiros agrupamentos sociais e o aparecimento das famílias. Disponível em: $<$ http://fabiopestanaramos.blogspot.com.br/2011/08/o-surgimento-do-homem-osprimeiros.html >. Acessado em 11/04/2017

RATTO, Luiz - Vendas técnicas de trabalho e mercado / Luiz Ratto - Rio de Janeiro: Senac Nacional, 2007.

SPIRO, R.L.; RICH, G.A.; STANTON, W.J. Gestão da força de vendas. Porto Alegre: AMGH, 2009.

STICKDORN; Marc. SCHNEIDER; Jacob - Isto é design thinking de serviços / marc stickdorn, Jacob Schneider e coautores; tradução: Mariana Bandarra; revisão técnica: Larissa biolchini. - porto alegre: bookman, 2014. 
